\title{
Application of preoperative assessment of pain induced by venous cannulation in predicting postoperative pain in patients under laparoscopic nephrectomy: a prospective observational study
}

\author{
Fei Peng, Yanshuang Li, Yanqiu Ai, Jianjun Yang and Yanping Wang*
}

\begin{abstract}
Background: Postoperative pain is the most prominent concern among surgical patients. It has previously been reported that venous cannulation-induced pain (VCP) can be used to predict postoperative pain after laparoscopic cholecystectomy within 90 mins in the recovery room. Its potential in predicting postoperative pain in patients with patient-controlled intravenous analgesia (PCIA) is worth establishing. The purpose of this prospective observational study was to investigate the application of VCP in predicting postoperative pain in patients with PCIA during the first $24 \mathrm{~h}$ after laparoscopic nephrectomy.

Methods: One hundred twenty patients scheduled for laparoscopic nephrectomy were included in this study. A superficial vein on the back of the hand was cannulated with a standard-size peripheral venous catheter $(1.1 \times 3.2$ $\mathrm{mm}$ ) by a nurse in the preoperative areas. Then the nurse recorded the VAS score associated with this procedure estimated by patients, and dichotomized the patients into low response group (VAS scores $<2.0$ ) or high response group (VAS scores 22.0 ). After general anesthesia and surgery, all the patients received the patient-controlled intravenous analgesia (PCIA) with sufentanil. The VAS scores at rest and on coughing at $2 \mathrm{~h}, 4 \mathrm{~h}, 8 \mathrm{~h}, 12 \mathrm{~h}, 24 \mathrm{~h}$, the effective number of presses and the number of needed rescue analgesia within $24 \mathrm{~h}$ after surgery were recorded.

Results: Peripheral venous cannulation-induced pain score was significantly correlated with postoperative pain intensity at rest $\left(r_{s}=0.64\right)$ and during coughing $\left(r_{s}=0.65\right)$, effective times of pressing $\left(r_{s}=0.59\right)$, additional consumption of sufentanil $\left(r_{s}=0.58\right)$. Patients with venous cannulation-induced pain intensity $\geq 2.0$ VAS units reported higher levels of postoperative pain intensity at rest $(P<0.0005)$ and during coughing $(P<0.0005)$, needed more effective times of pressing $(P<0.0005)$ and additional consumption of sufentanil $(P<0.0005)$, and also needed more rescue analgesia $(P=0.01)$ during the first $24 \mathrm{~h}$. The odds of risk for moderate or severe postoperative pain (OR 3.5, 95\% Cl 1.3-9.3) was significantly higher in patients with venous cannulation-induced pain intensity $\geq 2.0$ VAS units compared to those $<2.0$ VAS units.

(Continued on next page)
\end{abstract}

\footnotetext{
* Correspondence: 282243756@qq.com

Department of Anesthesiology, Pain and Perioperative Medicine, The First Affiliated Hospital of Zhengzhou University, No.1 Jianshe East Road,

Zhengzhou 450052, China
}

(c) The Author(s). 2020 Open Access This article is licensed under a Creative Commons Attribution 4.0 International License, which permits use, sharing, adaptation, distribution and reproduction in any medium or format, as long as you give appropriate credit to the original author(s) and the source, provide a link to the Creative Commons licence, and indicate if changes were made. The images or other third party material in this article are included in the article's Creative Commons licence, unless indicated otherwise in a credit line to the material. If material is not included in the article's Creative Commons licence and your intended use is not permitted by statutory regulation or exceeds the permitted use, you will need to obtain permission directly from the copyright holder. To view a copy of this licence, visit http://creativecommons.org/licenses/by/4.0/. The Creative Commons Public Domain Dedication waiver (http://creativecommons.org/publicdomain/zero/1.0/) applies to the data made available in this article, unless otherwise stated in a credit line to the data. 
(Continued from previous page)

Conclusions: Preoperative assessment of pain induced by venous cannulation can be used to predict postoperative pain intensity in patients with PCIA during the first $24 \mathrm{~h}$ after laparoscopic nephrectomy.

Trial registration: We registered this study in a Chinese Clinical Trial Registry (ChiCTR) center on July 62019 and received the registration number: ChiCTR1900024352.

Keywords: Venous cannulation, Pain, Postoperative pain, Pain prediction

\section{Background}

Postoperative pain is the most prominent concern among surgical patients. If not adequately controlled, it will affect postoperative rehabilitation, health-related quality of life, and may develop into persistent long-term pain [1-3].

Current postoperative pain management strategies apply a standardized, one-size-fits-all approach to all patients. These standardized protocols are not suitable for the significant difference in patient's pain and may lead to insufficient analgesia in patients with high analgesic needs, or excessive analgesia, which is accompanied by increasing analgesic-related side effects. The ability to preoperative predict who is at risk for developing moderate or severe postoperative pain might allow anaesthetists to optimize pain management by offering personalized, stratified or targeted analgesic treatment protocols. Preoperative pain prediction methods are highly relevant in this regard.

Numerous studies have tried to identify patients who are at risk for postoperative pain in the preoperative period and evaluated the role of psychological factors and experimental pain tests or quantitative sensory tests (QST) [4-8]. However, none of those prediction methods has been used as a routine for prediction of postoperative pain, mainly because expensive equipment, much time and effort are required outside routine preoperative procedures.

Peripheral venous cannulation, a routine procedure of preoperative preparation, induced pain intensity could be assessed easily and rapidly before surgery without specific equipment or training. It was recently shown that peripheral venous cannulation-induced pain (VCP) intensity could be used to predict the risk of postoperative pain. Patients with VCP score at or above 2.0 VAS units reported higher levels of acute postoperative pain intensity and more often have moderate or severe postoperative pain within 90 mins in the recovery room [9]. Its potential in predicting postoperative pain in patients with patient-controlled intravenous analgesia (PCIA) is worth establishing. The purpose of this study was to test if peripheral VCP intensity can be used to predict the risk for pain in patients with PCIA during the first $24 \mathrm{~h}$ after laparoscopic nephrectomy.

\section{Methods}

\section{Participants}

This prospective clinical observational study was approved by the Institutional Scientific Research and Clinical Trials
Ethics Committee of the First Affiliated Hospital of Zhengzhou University (ref.: 2019- KY-120) and registered at chictro.org (ref.: ChiCTR1900024352; July 6, 2019).

Patients who were classified as American Society of Anesthesiologists (ASA) physical status I-II, aged between 18 and 65 years, all genders, BMI 18 to $28 \mathrm{~kg} / \mathrm{m}^{2}$, and scheduled to undergo laparoscopic nephrectomy under general anaesthesia, agree to use postoperative analgesia pump for $48 \mathrm{~h}$ after surgery, agreed to cooperate and signed the informed consent were recruited.

Patients with the following conditions were excluded: severe heart, lung and metabolic diseases, hepatic or renal dysfunction, a history of neuromuscular system disease, mental illness, and a tendency to malignant hyperthermia, preoperative existing pain, long-term use of sedative and analgesic drugs ( $>3$ months), drug or alcohol abusers, or severe hypertension, poor understanding or communication difficulty, failed venous cannulation, changed in surgical approach (from laparoscopic to open surgery, the operative time over than $3 \mathrm{~h}$, failed to complete the data collection.

\section{Preoperative pain assessment}

An anaesthetist visited the patients the day before surgery, described the visual analogue scale (VAS) for them and instructed on the use of PCIA bump. On the day of surgery, an experienced nurse inserted a peripheral venous catheter (B. Braun Melsungen AG, Germany) with a standard-size $(1.1 \times 3.2 \mathrm{~mm}$ inner diameter) into a superficial vein on the back of the patient's hand in the preoperative preparation room. The patients were asked to estimate, on a horizontal VAS ruler, their maximum pain intensity associated with this procedure, recorded to one decimal point $(0.0-10.0)$. Then the nurse recorded the VAS score estimated (on a horizontal VAS ruler, their maximum pain score associated with this procedure) by the patients, and dichotomized the patients into low response group (VCP score $<2.0$ VAS units) or high response group (VCP score $\geq 2.0$ VAS units). The nurse was aware of whether the patient was to take part in the study.

\section{Anaesthesia}

All patients were anaesthetized by anaesthetists who were blinded to study and did not participate in data 
collection. Once in the operating room, the standardized monitoring of ECG, $\mathrm{SpO}_{2}$, noninvasive blood pressure was established. Before the induction of anaesthesia, the patients were given IV Penehyclidine Hydrochloride 0.5 $\mathrm{mg}$, and a loading dose of dexmedetomidine with $0.5 \mu \mathrm{g}$ $\mathrm{kg}^{-1}$ was infused over $10 \mathrm{~min}$. The bispectral index (BIS) was used to monitor the depth of anaesthesia. Then anaesthesia was induced with midazolam $2 \mathrm{mg}$, sulfentanil $0.5 \mu \mathrm{g} \mathrm{kg}^{-1}$, etomidate $2-3 \mathrm{mg} \mathrm{kg}^{-1}$. Cisatracurium 0.2 $\mathrm{mg} \mathrm{kg}{ }^{-1}$ was given to facilitate endotracheal intubation. Anaesthesia was maintained with sevoflurane (1-2\%), remifentanil $0.1-0.3 \mu \mathrm{g} \mathrm{kg}^{-1} \mathrm{~min}^{-1}$. The cisatracurium was used to provide a satisfactory level of muscle relaxation. The BIS value was maintained between 40 to 60 . The pneumoperitoneum pressure with carbon dioxide was set at $13-15 \mathrm{mmHg}$, and the $\mathrm{EtCO}_{2}$ was maintained at 35 to $45 \mathrm{mmHg}$. Thirty minutes before the end of the surgery, sulfentanil $10 \mu \mathrm{g}$ and flurbiprofen axetil $100 \mathrm{mg}$ were given as postoperative analgesia, and tropisetron 5 mg was given to prevent postoperative nausea and vomiting. At the end of the surgery, sevoflurane and remifentanil were stopped. Immediately after surgery, the PCIA pump was attached to the peripheral venous line by the anaesthetist. Then the patients were sent to the post anaesthetic care unit for anaesthetic resuscitation. All patients were sent to the general ward after being fully awake. Upon arrival in the general ward, all the patients were once again instructed on the use of the PCIA pump and VAS.

\section{Postoperative analgesia regimen}

The PCIA with sulfentanil regimen was applied to $48 \mathrm{~h}$ after surgery. The PCIA regimen consisted of sulfentanil $3.0 \mu \mathrm{g} \mathrm{kg}^{-1}$ and $5 \mathrm{mg}$ tropisetron, mixed with $0.9 \%$ normal saline to a total volume of $150 \mathrm{ml}$. The PCIA was programmed to deliver a $2 \mathrm{ml}$ bolus on demand, with a lock-out interval of $10 \mathrm{~min}$, and a background infusion rate of $2 \mathrm{ml} \mathrm{h}^{-1}$. In the ward, patients pressed PCA when VAS score at rest $>3.0$. If patients still reported pain or the VAS scores $\geq 4.0$, supplemental rescue boluses of intravenous flurbiprofen axetil injection of $50 \mathrm{mg}$ were administered. The complete history of continuous infusion, bolus infusion, and bolus demand for the PCIA device was downloaded after surgery.

\section{Outcome variables measures and data collection}

The study outcomes variables and the vital parameters were recorded at 2, 4, 8, 12 and $24 \mathrm{~h}$ after surgery. During the studied period, pain intensity, sulfentanil consumption, pressing times of the PCIA, and the number of rescue analgesia were recorded at above time points. Overall satisfaction index of the patients was recorded at $24 \mathrm{~h}$. Pain intensity was assessed with VAS at rest and during coughing.
The primary outcome was maximum postoperative pain scores at rest and during coughing within the first $24 \mathrm{~h}$. The secondary outcome was effective times of pressing, additional consumption of sulfentanil and satisfaction index at $24 \mathrm{~h}$. Also, the number of rescue analgesia within the first $24 \mathrm{~h}$ was also measured.

Postoperative data collector was blinded to the preoperative peripheral venous cannulation-induced pain score of the patients.

\section{Sample size and statistical analyses}

The sample size was based on a pilot experiment of 20 cases resulted in our observation that patients with $\mathrm{VCP}$ score $\geq 2.0$ VAS units was present in 8 out of 20 patients and that mean maximum postoperative pain score (VAS) at rest within $24 \mathrm{~h}$ after surgery was $3.9( \pm 1.3)$. Therefore, in order to show a $20 \%$ difference between the patients with VCP score $\geq 2.0$ VAS units and the patients with VCP score $\geq 2.0$ VAS units, the number of patients in each group was expected to be $41(\alpha=0.05$, $\beta=0.8$ ). Since the groups are unequal, assuming a $40 \%$ of patients with VCP score $\geq 2.0$ VAS units, and allow for up to $15 \%$ dropouts, a total of 120 patients (48 patients with VCP score $\geq 2.0$ VAS units and 72 patients with VCP score $<2.0$ VAS units) would be sufficient to test our hypothesis.

The IBM SPSS version 22.0 software packages were used for statistical analyses. The normality of the continuous data was tested by the Shapiro-Wilk test. Normally distributed continuous variables were expressed as mean \pm $\mathrm{SD}$ and compared between groups using a two-sample Student $t$-test. IF the distribution was not normal, the median with inter-quartile range (IQR) were expressed, and a Mann-Whitney $U$-test was used. Categorical data were expressed as frequency (n) and percentage (\%) and were statistically tested using the chi-square or Fisher's exact test. Correlations between variables were assessed with Spearman's rank correlation coefficients. Logistic regression analysis was used to evaluate the predictive abilities of cannulation-induced pain intensity. All $P$ values $<0.05$ were considered to be statistically significant.

\section{Results}

A total of 139 patients undergoing laparoscopic nephrectomy were screened between August and October 2019, of which 19 were excluded because they did not meet the inclusion criteria, refused to participate in the trial, and failed venous cannulation. Among the remaining 120 patients, some were eliminated due to transferred to ICU, converted to open surgery, surgery duration over 3 hours, or incomplete recording, and 106 study patients were available for analysis (Fig. 1).

Patients' demographic characteristics and perioperative data are shown in Table 1. The median (inter-quartile 


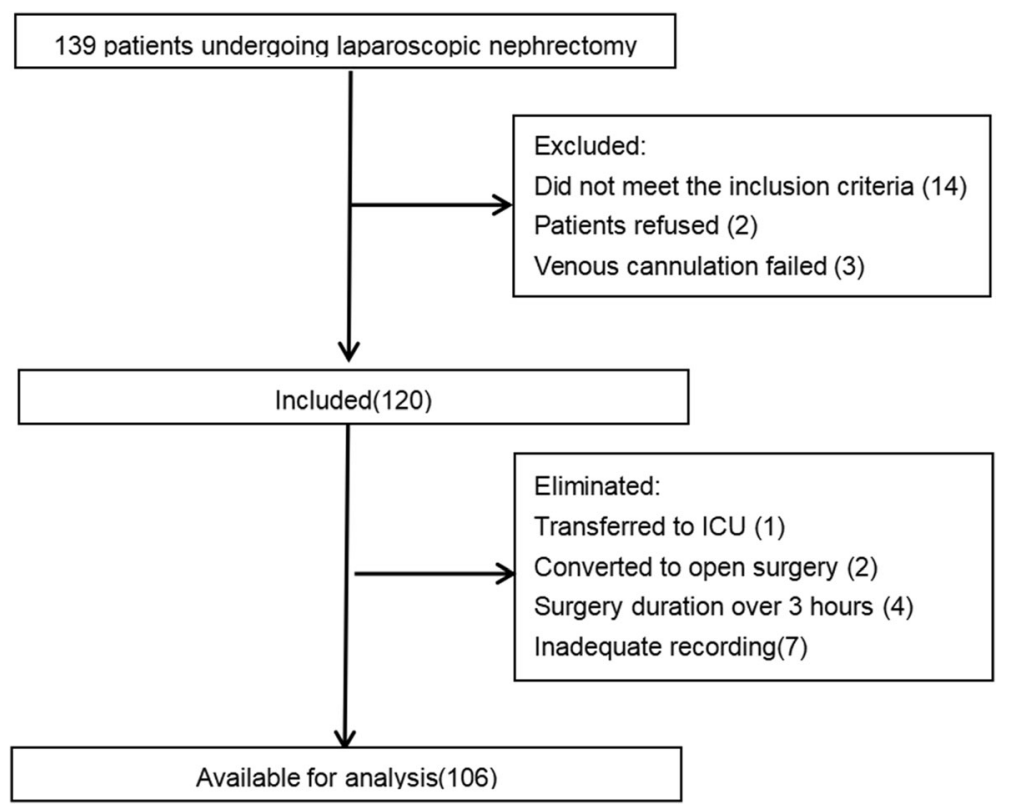

Fig. 1 Enrollment flow chart of patients

range) of peripheral venous cannulation-induced pain score, postoperative maximum pain score at rest, postoperative maximum pain score during coughing, effective times of pressing, additional consumption of sulfentanil were 1.8 (1.4-2.6), 3.4 (3.0-3.9), 5.8 (5.5-6.3), 1 (0-5), $3.18(0-12.56) \mu \mathrm{g}$. The cut-off point of classification according to VCP pain score (2.0 VAS units) was close to the median level of peripheral venous-induced pain score.

Bivariate correlations between peripheral venous cannulation-induced pain score and outcome variables are shown in Fig. 2 and Table 2. Postoperative maximum pain score at rest $\left(r_{s}=0.64, P<0.001\right)$ (Fig. 2a), postoperative maximum pain score during coughing $\left(r_{s}=0.65\right.$, $P<0.001)$ (Fig. 2b), effective times of pressing $\left(r_{s}=0.59\right.$, $P<0.001)$, additional consumption of sulfentanil $\left(r_{s}=0.58\right.$,

Table 1 Patients' demographic characteristics and perioperative data

\begin{tabular}{ll}
\hline Variable & \\
\hline Age (years) & $53(40-59)$ \\
\hline Gender (M/F) & $57 / 49$ \\
ASA (I/II) & $38 / 68$ \\
& $24.8(22.1-26.5)$ \\
Peripheral venous cannulation-induced pain score & $1.8(1.4-2.6)$ \\
Postoperative maximum pain score at rest & $3.4(3.0-3.9)$ \\
Postoperative maximum pain score during coughing & $5.8(5.5-6.3)$ \\
Effective times of pressing & $1(0-5)$ \\
Additional consumption of sulfentanil, $\mu \mathrm{g}$ & $3.18(0-12.56)$ \\
\hline
\end{tabular}

Data are presented as median (range) or number
$P<0.001)$ were statistically significantly correlated with peripheral venous cannulation-induced pain score, respectively.

Patients' demographic characteristics and perioperative data between the two groups are shown in Table 3 . There were no significant differences in age, gender, BMI, ASA, history of surgery, type of surgery, approaches of surgery, duration of anaesthesia and surgery, consumption of remifentanil between the two groups. Patients with venous cannulation-induced pain intensity $\geq 2.0$ VAS units reported higher levels of postoperative pain intensity at rest ( 3.7 vs. 3.2 VAS units; $P<0.0005)$ and during coughing (6.2 vs. 5.6 VAS units; $P<0.0005)$, needed more effective times of pressing ( 3 vs. $1 ; P<$ $0.0005)$ and additional consumption of sulfentanil (7.46 vs. $2.56 \mu \mathrm{g} ; P<0.0005)$, and also needed more rescue analgesia $(33.3 \%$ vs. $12.5 \%$; $P=0.01)$ during the first $24 \mathrm{~h}$. While the satisfaction index was significantly lower (3 vs.5; $P<0.0005)$.

The number of patients experiencing maximum pain (at rest) exceeding 4.0 VAS units during the first $24 \mathrm{~h}$ between high response group and low response group were shown in Table 4. In high response group, 33.3\% reported moderate or severe postoperative pain. While, in low response group, $12.5 \%$ reported moderate or severe pain. There was statistically significant in the risk for moderate or severe pain between two groups $(P=0.01)$.

After controlling for possible factors affecting postoperative pain (gender, age, history of surgery, type of surgery and approaches of surgery), the odds of risk for moderate or severe postoperative pain (OR 3.5, 95\% CI 1.3-9.3) was significantly higher in patients with venous 


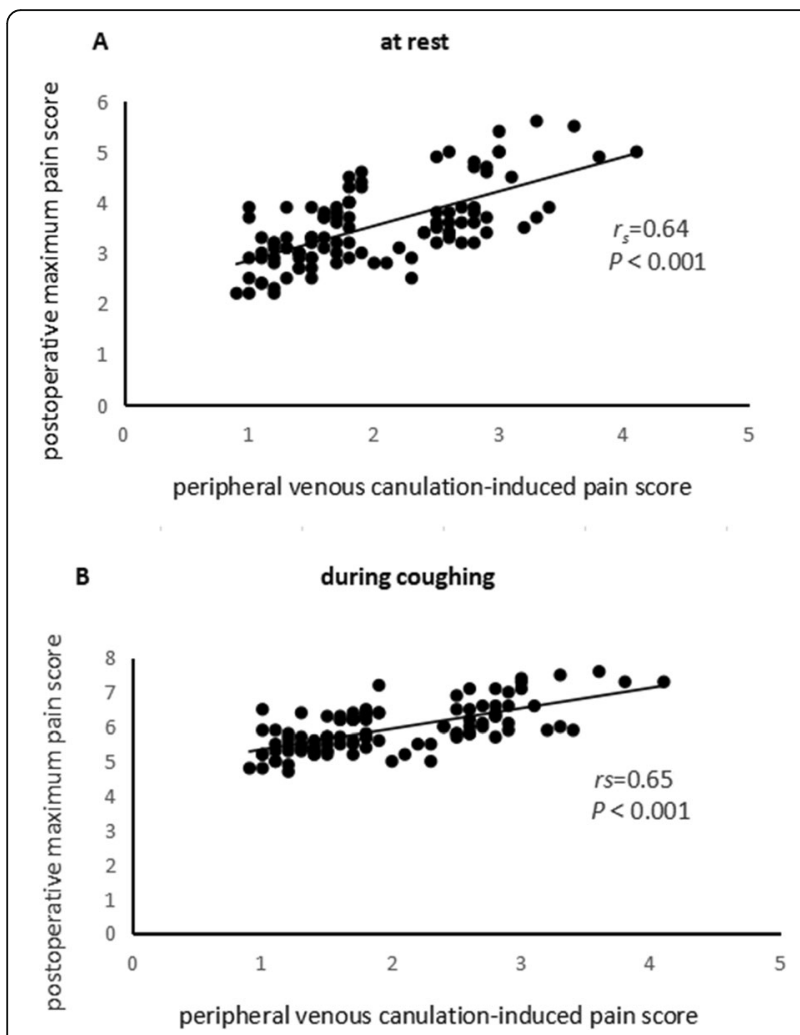

Fig. 2 Scatter plot of peripheral venous cannulation-induced pain score and postoperative maximum pain score (a) at rest, (b) during coughing

cannulation-induced pain intensity $\geq 2.0$ VAS units compared to those $<2.0$ VAS units (Table 5).

\section{Discussion}

This study shows that peripheral venous cannulationinduced pain score is positively correlated with postoperative maximum pain and addition consumption of sulfentanil during the first $24 \mathrm{~h}$ after laparoscopic nephrectomy. Patients with VCP score $\geq 2.0$ VAS units are more likely to report higher postoperative pain scores and additional consumption of sulfentanil. Furthermore, patients with VCP score $\geq 2.0$ VAS units have a 3.5 times higher risk for moderate or severe postoperative pain.

Peripheral venous cannulation, is a routine practice before surgery, has been reported by patients to be

Table 2 Bivariate correlations between venous cannulationinduced pain score and outcome variables

\begin{tabular}{ll}
\hline Postoperative maximum pain score at rest & $\begin{array}{l}\text { Correlation } \\
\text { coefficient }\left(r_{s}\right)\end{array}$ \\
Postoperative maximum pain score during coughing & $0.64^{*}$ \\
Effective times of pressing & $0.65^{*}$ \\
Additional consumption of sulfentanil, $\mu \mathrm{g}$ & $0.59^{*}$ \\
\hline
\end{tabular}

"meant $P<0.05$ painful. The pain intensity is associated with cannula site, cannula size, failed venipuncture attempts and process times $[10,11]$. In the present study, we did not include patients with failed venipuncture, and this procedure was performed by the experienced nurse with same diameter puncture needle on the same site. The results showed that the median level of pain intensity associated with venous cannulation on the hand was 1.8 VAS units, which was close to current study proposed the cut-off level of the VCP (2.0 VAS units). Furthermore, the cut-off level of the VCP was found to be 2.0 VAS units in predicting postoperative pain in Persson et al. Study [9]. Another study reported that 2.0 VAS units represented a more reasonable cut-off level of VCP for prediction of postoperative pain [12].

Prior researchers have also reported similar results to ours. Persson et al. [9] study reported that the VCP score was significantly correlated with postoperative maximum pain score at rest within 90 mins after laparoscopic cholecystectomy. Patients with VCP score $\geq 2.0$ VAS units had higher postoperative pain and risk for moderate or severe postoperative pain in the recovery room. However, the proportion of moderate or severe postoperative pain in patients with VCP score $\geq 2.0$ VAS units and $<2.0$ VAS units were higher than the present study reported. In our study, 33.3 and $12.5 \%$ of patients reported moderate or severe postoperative pain between patients with VCP score $\geq 2.0$ VAS units and $<2.0$ VAS units, while in Persson et al. [9] study, the proportions were 77 and $35 \%$. A possible explanation as to the difference is that patients are administered opioid through PCIA with continuous background infusion instead of on-demand. Carvalho et al. [13] study used VCP score to predict labor pain of 50 women and found that pain intensity of intravenous cannulation was correlated with time to epidural request during the course of induction of labour. A recently study [12] evaluated the usefulness of VCP score in 4 categories surgery (presumed to with hardly any postoperative pain, slight, moderate and severe levels of postoperative pain) and reported that the method of VCP score was only statistically significant in the patients subjected to surgery presumed to result in moderate levels of postoperative pain.

Numerous studies have been developed to predict postoperative pain in the last decade. The pain intensity of QST stimuli, including pressure, electric, and thermal stimulus, have been reported to correlate with the intensity of postoperative pain $[6-8,14-17]$. Werner et al. [18] reported that QST assessments might predict up to $54 \%$ of the variance in the postoperative pain experience. The predictive ability of the tests is much higher than previously reported for single-factor analyses of demographics and psychologic factors. However, these methods may be time-consuming and not necessarily available in a fast- 
Table 3 Demographic characteristics and perioperative data in patients dichotomized for peripheral venous cannulation-induced pain score

\begin{tabular}{|c|c|c|c|}
\hline & venous cannulat & re (VAS units) & \\
\hline & $<2.0$ & $\geq 2.0$ & $P$ values \\
\hline Total number of patients & 64 & 42 & \\
\hline Gender (M/F) & $39 / 25$ & $18 / 24$ & 0.068 \\
\hline Age (years) & $53(48-62)$ & $52(38-58)$ & 0.248 \\
\hline BMI $\left(\mathrm{kg} / \mathrm{m}^{2}\right)$ & $24.2(22.1-25.9)$ & $25.1(22.1-27.8)$ & 0.076 \\
\hline ASA $(I / I I)$ & $23 / 41$ & $15 / 27$ & 0.981 \\
\hline History of surgery (No/Yes) & $40 / 24$ & $22 / 20$ & 0.301 \\
\hline Type of surgery (Partial/Radical) & $24 / 40$ & $13 / 29$ & 0.489 \\
\hline $\begin{array}{l}\text { Approaches of surgery } \\
\text { (Retroperitoneal/Transperitoneal) }\end{array}$ & $15 / 49$ & $9 / 33$ & 0.809 \\
\hline Duration of anaesthesia, min & $134(100-157)$ & $133(113-170)$ & 0.339 \\
\hline Refentanil, mg & $1.05(0.80-1.40)$ & $1.10(1.00-1.36)$ & 0.361 \\
\hline Postoperative maximum pain score at rest & $3.2(2.9-3.7)$ & $3.7(3.4-4.7)$ & $<0.0005$ \\
\hline Postoperative maximum pain score on coughing & $5.6(5.3-6.2)$ & $6.2(5.8-7.0)$ & $<0.0005$ \\
\hline Additional consumption of sulfentanil, $\mu \mathrm{g}$ & $2.56(0-7.86)$ & $7.46(2.71-22.91)$ & $<0.0005$ \\
\hline Effective times of pressing & $1(0-3)$ & $3(1-8)$ & $<0.0005$ \\
\hline Needed rescue analgesia & $8(12.5 \%)$ & $14(33.3 \%)$ & 0.01 \\
\hline satisfaction index & $5(4-5)$ & $3(3-4)$ & $<0.0005$ \\
\hline
\end{tabular}

Variables are presented as median (range) or number

paced clinical environment. The VCP assessment is easy to perform, timely and rapid clinical test and requires no special equipment.

Our finding has important clinical implications since pain management in the postoperative period still present a challenge. There is large individual variability in response to opioids and the potential side effects such as respiratory depression, nausea, vomiting and constipation. The ability to preoperative identification of patients at greater risk for moderate or severe postoperative pain and having higher opioids requirements is very beneficial. Using peripheral VCP intensity as a predictor of postoperative pain may allow anaesthetists more convenient to adjust the dosage of opioids and can potentially improve postoperative pain management.
There are some limitations to the present study. Known risk factors of postoperative pain are female gender, lower age, preoperative pain, intraoperative factors and psychological factors, and so on $[8,19-21]$. Furthermore, it was reported that psychological factors were correlated with venous cannulation-induced pain score [22]. This study did not take psychological factors into account. The psychological variables may affect the levels of postoperative pain and venous cannulationinduced pain score. Besides, this method did not be evaluated in other surgical patients.

\section{Conclusions}

In conclusion, peripheral venous cannulation-induced pain score was associated with postoperative pain and

Table 4 Cross-tabulation for a prediction model for maximum postoperative pain according to peripheral venous cannulationinduced pain score

$\begin{array}{lll}\frac{\text { Venous cannulation-induced pain score (VAS units) }}{<2.0} & \text { Total } \\ & \geq 2.0 & \text { number } \\ & \text { of } \\ & \text { patients }\end{array}$

Patients reporting maximum postoperative pain intensity at rest (VAS units)

\begin{tabular}{|c|c|c|c|}
\hline$<4$ & $56(87.5 \%)$ & $28(66.7 \%)$ & 84 \\
\hline$\geq 4$ & $8(12.5 \%)$ & $14(33.3 \%)$ & 22 \\
\hline otal number of patients & 64 & 42 & 106 \\
\hline
\end{tabular}

Comparison of the number of patients experiencing pain exceeding VAS 4.0 within $24 \mathrm{~h}$ between high response group and low response group $(P=0.01)$ 
Table 5 Logistic regression analysis of the ability of venous cannulation-induced pain score ( $\geq /<2.0$ VAS units) to predict postoperative pain intensity $\geq 4.0$ VAS units

\begin{tabular}{lcc}
\hline \multicolumn{3}{c}{ multivariate analysis } \\
\cline { 2 - 3 } OR(95\% Cl) & $P$ value \\
\hline Venous cannulation-induced pain score (VAS units) & \\
$<2.0$ & $1.0($ ref $)$ & 0.012 \\
$\geq 2.0$ & $3.5(1.3-9.3)$ & \\
\hline
\end{tabular}

Abbreviations $=\mathrm{OR}$ (odds ratio), $\mathrm{Cl}$ (confifidence interval) The model adjusted for gender, age, history of surgery, type of surgery and approaches of surgery

addition consumption of sulfentanil during the first 24 $\mathrm{h}$ after laparoscopic nephrectomy. Patients with VCP score $\geq 2.0$ VAS units had higher postoperative pain scores, additional consumption of sulfentanil and risk for moderate or severe postoperative pain. Therefore, peripheral venous cannulation-induced pain intensity can be considered as a simple and useful method to predict postoperative pain in patients with PCIA during the first $24 \mathrm{~h}$ after laparoscopic nephrectomy.

\section{Abbreviations}

VCP: Venous cannulation-induced pain; PCIA: Patient-controlled intravenous analgesia; VAS: Visual analogue scale; QST: Quantitative sensory tests; ASA: American Society of Anesthesiologists; BMI: Body mass index

\section{Acknowledgements}

This research was supported by the department of Urinary surgery at the First Affiliated Hospital of Zhengzhou University. The authors thank Jian Li, Lang Yan, and Xuepei Zhang for performing the operation.

\section{Authors' contributions}

FP contributions to the study concept and design, acquisition of data, analysis and interpretation of data, drafting and revising the manuscript. YSL contributions to the study design, acquisition of data. YQA contributions to the study concept and design. JJY helped revise the manuscript. YPW contribution to the study concept and design, analysis and interpretation of data, revising the manuscript. All authors read and approved of the final manuscript.

\section{Funding}

The authors received no funding for this study.

\section{Availability of data and materials}

The datasets generated and analysed during the current study are available from the corresponding author on reasonable request.

\section{Ethics approval and consent to participate}

This study was approved by the Institutional Scientific Research and Clinical Trials Ethics Committee of the First Affiliated Hospital of Zhengzhou University on June 12, 2019. This study was also registered at chictro.org (ChiCTR1900024352). Written informed consent was obtained from all of the participants.

\section{Consent for publication}

Not applicable.

\section{Competing interests}

The authors declare that they have no competing interests.
Received: 17 January 2020 Accepted: 6 April 2020

Published online: 18 April 2020

\section{References}

1. Glare P, Aubrey KR, Myles PS. Transition from acute to chronic pain after surgery. Lancet. 2019;393(10180):1537-46. https://doi.org/10.1016/S01406736(19)30352-6

2. Gan TJ, Habib AS, Miller TE, White W, Apfelbaum JL. Incidence, patient satisfaction, and perceptions of post-surgical pain: results from a US national survey. Curr Med Res Opin. 2014;30(1):149-60. https://doi.org/10.1185/ 03007995.2013.860019.

3. Lavand'homme P. Transition from acute to chronic pain after surgery. Pain. 2017;158 Suppl 1:S50-S54;doi:https://doi.org/10.1097/j.pain. 0000000000000809

4. Pan PH, Tonidande AM, Aschenbrenner CA, Houle TT, Harris LC, Eisenach JC. Predicting acute pain after cesarean delivery using three simple questions. Anesthesiology. 2013;118(5):1170-9. https://doi.org/10.1097/ALN. Ob013e31828e156f

5. Rehberg B, Mathivon S, Combescure C, Mercier Y, Savoldelli GL. Prediction of acute postoperative pain following breast cancer surgery using the pain sensitivity questionnaire: a cohort study. Clin J Pain. 2017;33(1):57-66.

6. Buhagiar LM, Cassar OA, Brincat MP, Buttigieg GG, Inglott AS, Adami MZ, et al. Pre-operative pain sensitivity: a prediction of post-operative outcome in the obstetric population. J Anaesthesiol Clin Pharmacol. 2013;29(4):46571. https://doi.org/10.4103/0970-9185.119135.

7. Werner MU, Jensen EK, Stubhaug A. Preoperative quantitative sensory testing (QST) predicting postoperative pain: image or mirage? Scand J Pain. 2017;15:91-2. https://doi.org/10.1016/j.sjpain.2017.01.012.

8. Gamez BH, Habib AS. Predicting severity of acute pain after cesarean delivery: a narrative review. Anesth Analg. 2018;126(5):1606-14. https://doi. org/10.1213/ANE.0000000000002658

9. Persson AK, Pettersson FD, Dyrehag LE, Åkeson J. Prediction of postoperative pain from assessment of pain induced by venous cannulation and propofol infusion. Acta Anaesthesiol Scand. 2016;60(2):166-76. https:// doi.org/10.1111/aas.12634

10. Goudra BG, Galvin E, Singh PM, Lions J. Effect of site selection on pain of intravenous cannula insertion: a prospective randomised study. Int J Anesth. 2014;58:732-5. https://doi.org/10.4103/0019-5049.147166.

11. Rüsch $D$, Koch $T$, Spies $M, H j$ Eberhart L. Pain during venous cannulation. Dtsch Arztebl Int. 2017;114(37):605-11. https://doi.org/10.3238/arztebl.2017. 0605.

12. Persson AK, Åkeson J. Prediction of acute postoperative pain from assessment of pain associated with venous catheterization. Pain Prac. 2019; 19(2):158-67. https://doi.org/10.1111/papr.12729.

13. Carvalho B, Zheng M, Aiono-Le TL. Evaluation of experimental pain tests to predict labour pain and epidural analgesic consumption. Br J Anaesth. 2013; 110(4):600-6. https://doi.org/10.1093/bja/aes423.

14. Buhagiar L, Cassar OA, Brincat MP, Azzopardi LM. Predictors of postcaesarean section pain and analgesic consumption. J Anaesthesiol Clin Pharmacol. 2011;27(2):185-91. https://doi.org/10.4103/0970-9185.81822.

15. Wilder-Smith $\mathrm{CH}$, Hill L, Dyer RA, Torr G, Coetzee E. Postoperative sensitization and pain after cesarean delivery and the effects of single im doses of tramadol and diclofenac alone and in combination. Anesth Analg. 2003;97(2):526-33.

16. Granot M, Lowenstein L, Yarnitsky D, Tamir A, Zimmer EZ. Postcesarean section pain prediction by preoperative experimental pain assessment. Anesthesiology. 2003;98(6):1422-6.

17. Strulov L, Zimmer EZ, Granot M, Tamir A, Jakobi P, Lowenstein L. Pain catastrophizing, response to experimental heat stimuli, and post-cesarean section pain. J Pain. 2007;8(3):273-9.

18. Werner MU, Mjöbo HN, Nielsen PR, Rudin A. Prediction of postoperative pain: a systematic review of predictive experimental pain studies. Anesthesiology. 2010;112:1494-502. https://doi.org/10.1097/ALN. Ob013e3181dcd5a0

19. Richebé $P$, Capdevila X, Rivat C. Persistent postsurgical pain: pathophysiology and preventative pharmacologic considerations. Anesthesiology 2018;129(3):590-607; doi:https://doi.org/10.1097/ALN. 0000000000002238.

20. Horn-Hofmann C, Scheel J, Dimova V, Parthum A, Carbon R, Griessinger N, et al. Prediction of persistent post-operative pain: pain-specific psychological variables compared with acute post-operative pain and 
general psychological variables. Eur J Pain. 2018;22(1):191-202. https://doi. org/10.1002/ejp.1115.

21. Tan CO, Chong YM, Tran P, Weinberg L, Howard W. Surgical predictors of acute postoperative pain after hip arthroscopy. BMC Anesthesiol. 2015;15:96. https://doi.org/10.1186/s12871-015-0077-x.

22. Suren M, Kaya Z, Gokbakan M, Okan I, Arici S, Karaman S, et al. The role of pain catastrophizing score in the prediction of venipuncture pain severity. Pain Pract. 2014;14(3):245-51. https://doi.org/10.1111/papr.12060.

\section{Publisher's Note}

Springer Nature remains neutral with regard to jurisdictional claims in published maps and institutional affiliations.

Ready to submit your research? Choose BMC and benefit from:

- fast, convenient online submission

- thorough peer review by experienced researchers in your field

- rapid publication on acceptance

- support for research data, including large and complex data types

- gold Open Access which fosters wider collaboration and increased citations

- maximum visibility for your research: over $100 \mathrm{M}$ website views per year

At $\mathrm{BMC}$, research is always in progress.

Learn more biomedcentral.com/submissions 